\title{
Effects of different pre-cementation cleaning protocols on adhesive bond strength in indirect composite resin restorations contaminated with saliva.
}

\author{
Claudia Cañete ${ }^{1}$, Catalina Guerrero ${ }^{2}$, Ana Martínez ${ }^{2}$, Elizabeth Gaete ${ }^{2}$
}

\section{ABSTRACT}

Objective: Compare the effects of different pre-cementing cleaning protocols on adhesive bond strength (MPa) in indirect composite resin restorations contaminated with saliva.

Materials and Methods: 110 test bodies of indirect composite resin, divided in two groups: with no contamination (NC); with contamination (WC); distributed in 22 subgroups $(n=5)$ according to the Ultrasound $(U)$ variables; Cleaning Paste (CP); Ethanol $96^{\circ}(\mathrm{E})$, Application times: 5-20-30-180s. Five cylinders ( $1 \mathrm{~mm}$ high $\times 0.7 \varnothing)$ of cement (Variolink Esthetic LC) per sample made on treated and light-cured surfaces (20s). After $24 \mathrm{hrs} / 37^{\circ} \mathrm{C}+$ distilled water, they were subjected to the RUA test $(0.5 \mathrm{~mm} / \mathrm{min})$ until fracture point in a universal test machine. Analyzed with one-way ANOVA and post hoc Tukey test $(\alpha=0.05)$.

Results: Contaminated CP30" was the protocol with the highest binding resistance $(14.57 \pm 1.01)(p<0.05)$.

Conclusion: The gold standard technique - corresponding to ultrasonic washing - is unrecommended for cleaning indirect composite resin restoration, seen as there are other more effective protocols to eliminate surface contaminants. Cleaning paste and Ethanol in times of 20 " or 30 " are suggested.
1. DDS, graduate of aesthetic dentistry and professor at the University of Valparaíso, Chile.

2. DDS, Chile.

Correspondence:

Dra. Claudia Cañete

Email: Claudia.canete@uv.cl

KEYWORDS:

indirect composite; dental resins; cementation; saliva. 


\section{INTRODUCTION}

The increasing use of resin composites in the last few years has meant the improvement of its physical-mechanical properties and bonding systems ${ }^{1-4}$. However, deficiencies of direct composite resin persist that are expected to be resolved through the indication of indirect resins when the loss of dental structure is more significant. Among these last-mentioned techniques, the cementation process is crucial for both the restoration as its clinical performance and longevity ${ }^{5,6}$.

Amid the critical steps of indirect resins are the pre-cementation procedures that consider the surface's cleansing and conditioning. This step can be vulnerable to contamination of fluids during intraoral adjustments tests ${ }^{7,8}$. Saliva contamination is one of the most frequent causes of bonding failure ${ }^{9,10}$. Contamination before or during cementation may lead to a decreased quality of linking, leading to adverse effects on longevity and maintenance of restoration, sensitivity, and discoloration ${ }^{11}$.

Different pre-cementation protocols are described in the literature: Ethanol ${ }^{2,12,13}$, Chlorhexidine (CHX), Orthophosphoric Acid (AO), and Ultrasonic Washer ${ }^{14}$. In 2015 Ivoclean cleaning paste (Ivoclar Vivadent AG, Schaan, Liechtenstein) was introduced, an alkaline suspension of zirconium oxide and sodium hydroxide particles ${ }^{15}$. The different cleaning protocols have not been the main focus of research, so it is unclear whether surface cleaning methods effectively improve the cement/resin bond. In addition, there is no standardization within the protocols of the time required and the ones that most effectively eliminate contamination ${ }^{15}$.

Therefore, the purpose of this study was to compare the effect of different precementation cleaning protocols on adhesive bond strength (MPa) in indirect composite resin restorations contaminated with saliva.

\section{MATERIAL Y MÉTODOS}

A quantitative, experimental in vitro study that aimed to compare the effect of different precementation cleaning protocols on adhesive bond strength of indirect composite resin restorations (ICR) contaminated with saliva through the micro-shear test.

The sample was non-probabilistic. The operator selected test bodies by default by a simple randomized list. For the calculation, protocols available in the literature were considered, concerning the control groups, a mean value of (30 MPa) and standard deviation (10.5) of the binding resistance were selected.

In this approach, a magnitude of effect (20 $\mathrm{MPa}$ ) was determined for the experimental groups, which were composed of 5 minimum test bodies per group $(n=5)$, this value was obtained through a superiority calculation test considering a significance level of $5 \%$ and a power of $80 \% 14$. In the literature, there were necessary 5 test bodies per group to observe a detectable effect magnitude among the control and experimental groups. The materials used presented high homoscedasticity, and the evaluation technique used, a high sensitivity.

The independent variables studied were the pre-cementation cleaning protocol, the application time measured in seconds, and the contamination of the samples, which were considered as nominal qualitative variables, continuous quantitative and nominal qualitative, respectively. The dependent variable studied was the adhesive bond strength, which was continuous quantitative, measured in MPa.

The research began with the calibration by conformity of the evaluators regarding the methodological stages: preparation of the test body's surface; restoration itself, and traction of the samples. The evaluators entered the laboratory with gloves, a mask, a medical apron over scrubs, and protective glasses for handling ethanol and sodium hydroxide solution, which can cause irritation on contact 
with skin or mucous membranes.

110 sample bodies of RCI In: Joy were prepared, which were polymerized in Dentsply's Triad 2000 photo activator unit, fixed in modeling compound inside polyvinyl chloride cylinders.

Posteriorly, they were distributed into 22 groups $(\mathrm{n}=5)$, considering 4 control groups and according to the following variables: contamination with saliva (no contamination $[\mathrm{NC}]$ and with contamination [WC]); Cleaning protocols (Ultrasound [U], Ethanol $96^{\circ}$ [E], Sodium Hydroxide Solution [HS]) and Application times (5, 20 and 30 seconds) (Table I.)

The surfaces were regularized, washed, and dried; each resin block's perimeter was marked with a graphite pencil, positioning it on a double-sided tape, removed, and perforations were made with a rubber perforator within the mark. Then the surfaces were regularized, washed, and dried again.

Subsequently, half of the samples (11 groups) were contaminated. They were soaked in saliva for 60 seconds, rinsed with water spray for 15 seconds, and blown dry for 15 seconds.
Saliva was obtained from a donor with no relevant systemic history, periodontal disease, or active caries, who fasted for 12 hours and did not consume fluids 2 hours before collection.

The different pre-cementation protocols were applied, depending on the group. In group U, ultrasonic cleaning was used for 5, 20, 30 seconds in distilled water and dried with air during the same application time. In group $\mathrm{E}$, cleaning was carried out with denatured ethanol at $96^{\circ}$ with a microbrush rubbed for 5,20 , and 30 seconds, followed by air-drying during the same application time. In the CP group, Ivoclean (Ivoclar Vivadent) was applied and permitted to react for 5, 20, and 30 seconds, rinsed with water and dried for the same application time.

Control groups considered test bodies contaminated and with no contamination. The positive controls were established. The gold standard pre-cementation protocol (180 seconds of ultrasonic washing) was applied, and negative controls to which no precementation protocol was applied. In this form, 4 subgroups are counted: positive and negative "with contamination", and positive and negative "no contamination" subgroups.

Afterward, the cementation was performed, the

Table I: Experimental matrix of pre-cementation cleaning protocols, application times, and level of contamination

\begin{tabular}{|c|c|c|c|c|c|c|}
\hline & \multicolumn{3}{|c|}{ NO CONTAMINATION } & \multicolumn{3}{|c|}{ WITH CONTAMINATION } \\
\hline $\begin{array}{c}\text { Cleaning } \\
\text { protocols/T } \\
\text { (seconds) }\end{array}$ & $5 "$ & $20 "$ & $30 "$ & $5 "$ & $20 "$ & $30 "$ \\
\hline $\mathrm{U}$ & U5"NC & U20"NC & U30"NC & U5"WC & U20"WC & U30"WC \\
\hline $\mathrm{E}$ & E5"NC & E20"NC & E30"NC & E5"WC & E20"WC & E30"WC \\
\hline $\mathrm{CP}$ & CP5"NC & $\mathrm{CP} 20$ "NC & CP30"NC & CP5"WC & CP20"WC & CP30"WC \\
\hline $\mathrm{C}+$ & \multicolumn{3}{|c|}{ U180" NC } & \multicolumn{3}{|c|}{ U180" WC } \\
\hline C- & \multicolumn{3}{|c|}{ NEGATIVE } & \multicolumn{3}{|c|}{ NEGATIVE } \\
\hline
\end{tabular}

U: Ultrasound, E: Ethanol 96º, CP: cleaning paste, C+: positive control; C-: Negative control, NC: No contamination, WC: With contamination. 
double-sided tape was positioned, adapting it with a blunt-tipped instrument over each tape perforation. The Monobond $\mathrm{N}$ surface treatment was applied for 60 seconds with a microbrush and air-dried for 10 seconds. The non-adherent part of the tape was removed and positioned over each perforation, using an OLYMPUS SZ60 binocular loupe, a rubber cylinder (Tygon) matching the opening of this with the perforation.

In each Tygon, Variolink Esthetic LC Neutral resin cement (Ivoclar Vivadent) was applied until it was filled to be photoactivated with an LED lamp for 20 seconds (Bluephase $\mathrm{N}$, Ivoclar Vivadent). The samples were kept for 24 hours in distilled water at $37^{\circ} \mathrm{C}$ in a culture oven. Once the test bodies were obtained, the micro-shear test, with a constant load, was applied in a Microtensile OM 100 testing machine at a speed of $0.5 \mathrm{~mm} / \mathrm{min}$ until the fracture point.

Before performing the statistical analysis, the Kolmogorov - Smirnov test concluded that the working groups presented normal distribution behavior. A descriptive statistical analysis was also applied to each group of data. The Skewness and Kurtosis coefficient was calculated to corroborate that the samples were within theoretical normal distribution ranges.

One-factor ANOVA was applied as inferential statistics with a significance level of $95 \%$ to compare the different pre-cementation cleaning protocols and the times, and then apply Tukey's post hoc test to perform the multiple comparison analysis.

The positive control group obtained the lowest results of all the protocols (11.92 \pm $0.94)$; therefore, all the other proposed protocols achieved results superior or similar to this one. In the application at 5 seconds, the three cleaning protocols achieved similar results to the positive control, but in a shorter time.

Contrastingly, in the groups contaminated with saliva, the best results, which also managed to surpass both control groups in their respective times, were achieved by:

- The cleaning paste applied for 20 and 30 seconds $(12.93 \pm 1.00$ and $14.57 \pm 1.01)$.

- $\quad$ Ethanol applied for 30 seconds (13.48 \pm $0.77)$.

Similar to the previous situation, the positive control group obtained the lowest results $(9.93 \pm$ 0.71). In the application at 5 seconds, the three cleaning protocols achieved similar results to the positive control, but in a shorter time. It should be noted that ultrasound achieved similar results to both control groups $(9.93 \pm 0.71$ and $9.64 \pm$ $0.63)$ in all its application times (10.16 \pm 0.86 , $10.23 \pm 0,89$, and $10.14 \pm 1.15)$.

As a general rule, the contaminated groups with saliva obtained a lower adhesive bond strength than the non-contaminated groups, which was statistically significant in all cleaning protocols and application times. (Fig. 1 and Table II.).

\section{RESULTS}

Regarding the groups with no contamination, the cleaning protocols that achieved the best results, obtaining adhesive bond strength values higher than the controls were:

- The cleaning paste applied for 20 and 30 seconds $(17.18 \pm 1.13$ and $19.51 \pm 1.3)$.

- Ethanol applied for 20 and 30 seconds $(18.48 \pm 0.90$ and $20.17 \pm 0.95)$

\section{DISCUSSION}

One of this research main findings is that most of the cleaning protocols managed to influence the adhesive bond strength by having statistically superior results than the control groups. This could be explained by their action on the resin surface, where they could eliminate contaminants improving adhesion and increasing the adhesive bond strength. Previous authors have attested that different cleaning protocols influence the adhesive bond strength in ceramic restorations ${ }^{16}$; In the present study, the authors used a different restoration material (indirect resin composite), obtaining similar results, nonetheless. 
Table II: Summary of results regarding mean resistance and confidence intervals in different protocols at 5, 20 and 30 seconds, and degree of contamination.

\begin{tabular}{|c|c|c|c|c|c|c|}
\hline & \multicolumn{3}{|c|}{ NO CONTAMINATION } & \multicolumn{3}{|c|}{ WITH CONTAMINATION } \\
\hline $\begin{array}{c}\text { Cleaning } \\
\text { protocols/T } \\
\text { (seconds) }\end{array}$ & $5^{\prime \prime}$ & $20 "$ & $30 "$ & $5^{\prime \prime}$ & $20 "$ & $30 "$ \\
\hline $\mathrm{U}$ & $\begin{array}{c}10,16 \pm 0,8 \\
6 \mathrm{~A}, \mathrm{a}\end{array}$ & $\begin{array}{c}10,23 \pm 0,8 \\
9 \mathrm{~B}, \mathrm{a}\end{array}$ & $\begin{array}{c}10,14 \pm 1,1 \\
5 \mathrm{~B}, \mathrm{a}\end{array}$ & $\begin{array}{c}13,78 \pm 0,7 \\
5 \mathrm{~B}, \mathrm{ab}\end{array}$ & $\begin{array}{c}15,11 \pm 0,7 \\
2 \mathrm{~B}, \mathrm{a}\end{array}$ & $\begin{array}{c}13,02 \pm 1,2 \\
6 \mathrm{~B}, \mathrm{~b}\end{array}$ \\
\hline $\mathrm{E}$ & $\begin{array}{c}8,95 \pm 1,46 \\
\text { A,c }\end{array}$ & $\begin{array}{c}11,43 \pm 1,1 \\
5 \mathrm{AB}, \mathrm{b}\end{array}$ & $\begin{array}{c}13,48 \pm 0,7 \\
7 \mathrm{~A}, \mathrm{a}\end{array}$ & $\begin{array}{c}17,24 \pm 1,4 \\
0 \mathrm{~A}, \mathrm{~b}\end{array}$ & $\begin{array}{c}18,48 \pm 0,9 \\
0 \mathrm{~A}, \mathrm{ab}\end{array}$ & $\begin{array}{c}20,17 \pm 0,9 \\
5 \mathrm{~A}, \mathrm{a}\end{array}$ \\
\hline $\mathrm{CP}$ & $\begin{array}{c}11,04 \pm 1,5 \\
0 \mathrm{~A}, \mathrm{~b}\end{array}$ & $\begin{array}{c}12,93 \pm 1,0 \\
0 \mathrm{~A}, \mathrm{ab}\end{array}$ & $\begin{array}{c}14,57 \pm 1,0 \\
1 \mathrm{~A}, \mathrm{a}\end{array}$ & $\begin{array}{c}13,95 \pm 1,4 \\
0 \mathrm{~B}, \mathrm{c}\end{array}$ & $\begin{array}{c}17,18 \pm 1,1 \\
3 \mathrm{~A}, \mathrm{~b}\end{array}$ & $\begin{array}{c}19,51 \pm 1,3 \\
1 \mathrm{~A}, \mathrm{a}\end{array}$ \\
\hline $\mathrm{C}+$ & & $9,93 \pm 0,71$ & & & $11,92 \pm 0,94$ & \\
\hline $\mathrm{C}-$ & & $9,64 \pm 0,63$ & & & $13,13 \pm 2,22$ & \\
\hline
\end{tabular}

U: Ultrasound, E: Ethanol 96º, CP: cleaning paste, C+: positive control; C-: Negative control, NC: No contamination, WC: With contamination.

Figure 1: Results of the bond strength to micro-shear in Megapascals, using the different cleaning protocols at 5,20 , and 30 seconds on the test bodies with varying contamination degrees.

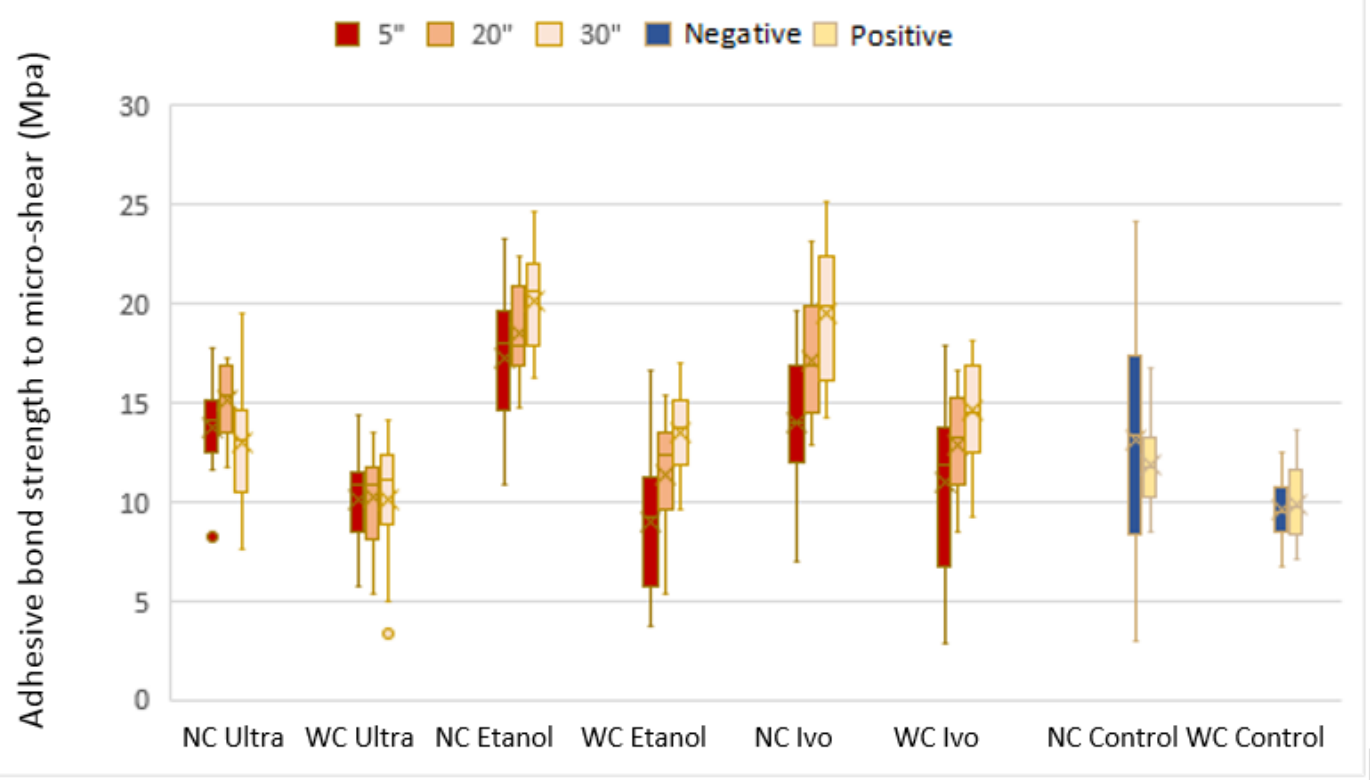

Ultra: Ultrasound, Ivo: Ivoclear cleaning paste. Mpa: Megapascals 
It was noted that the application times influenced the adhesive bond strength with the cleaning paste and ethanol protocol, which, applied for 20 and 30 seconds, achieved better results, being statistically superior to the control groups. Likewise, Muñoz (2017) analyzed different cleaning protocols, where he managed to conclude that the application times of the protocols influence the adhesive bond strength ${ }^{14}$.

Regarding contamination with saliva, it was registered that this reduces the adhesive bond strength, in view of the fact that after this contamination occurs, non-covalent adsorption of salivary proteins is expected to occur, which produces an organic adhesive coating in the first seconds, which is resistant to rinsing with water, and negatively affecting the bonding of cement and restorations ${ }^{17-19}$. Likewise, authors have shown that contamination with saliva reduces adhesive bond strength ${ }^{19,20}$.

When analyzing the groups that were not contaminated, the results with ethanol in its 3 application times stood out, while when analyzing the contaminated groups, one of the best results was obtained with ethanol when applied at 20 and 30 seconds. Consequently, ethanol represents a good alternative for the clinician due to its accessibility, multiple uses, and excellent results shown in the precementation cleaning of indirect composite resins. Similarly, other authors have described that ethanol, when used as a pre-cementation cleaning element, manages to eliminate contaminants from the resin's surface ${ }^{21,22}$.

Regarding the cleaning paste at 20 and 30 seconds, it achieved one of the best results in both contaminated and uncontaminated groups. According to the manufacturer, this consists of an alkaline suspension of zirconium oxide particles that bind to the phosphate contaminants in saliva, obtaining a cleaner surface. This study is the first to use the cleaning paste in indirect composite resin restorations, previously it had only been studied in ceramic and zirconium restorations showing good results in removing contaminants and improving the cement-restoration bond ${ }^{15-18}$. Therefore, it is a useful alternative for the clinician, for even though it has a higher cost than other options, it has the advantage of being able to be used on more than one type of substrate.

The ultrasound protocol obtained results similar to those of the control groups, and the gold standard technique obtained one of the lowest results of all the protocols studied. This may be due to the fact that ultrasound has been used for cleaning ceramic restorations after etching with hydrofluoric acid, which produces a precipitate that adheres to the surface of the restorations and is eliminated with the ultrasound process; however, by not using it on composite resin restorations, this method would not be effective enough to remove contaminants from the surfaces of these restorations.

\section{CONCLUSION}

According to the results obtained, it was concluded that the gold standard technique corresponding to ultrasonic washing is not recommended for the cleaning of indirect composite resin restorations; furthermore, it was shown that there are other effective protocols, at a low application time, that eliminate contaminants from these restorations, which also implies a reduction in clinical times.

\section{CONFLICTS OF INTEREST}

No Conflicts of Interest

\section{REFERENCIAS}

[1] D'Arcangelo C, Vanini L. Effect of three surface treatments on the adhesive properties of indirect composite restorations. J Adhes Dent. 2007 Jun;9(3):319-26.

[2] Hamano N, Chiang Y, Nyamaa I, Yamaguchi $\mathrm{H}$, Ino $\mathrm{S}$, et al. Repair of silorane-based dental composites: Influence of surface treatments. Dental Materials 28 2012; 894-902.

[3] Harorli OT, Barutcugil C, Kirmali D, Kapdan A. "Shear bond strength of a 
self-etched resin cement to an indirect composite: Effect of different surface treatments" Nigerian Journal of Clinical Practice. 2016;18(3):40510

[4] Barabanti N, Preti A, Vano M, Derchi $G$, et al. Indirect composite restorations luted with two different procedures: A ten years follow up clinical trial. J Clin Exp Dent. 2015;7(1):54-9

[5] Cura M, González-González I, Fuentes V, Ceballos L. Effect of surface treatment and aging on bond strength of composite resin onlays. J Prosthet Dent. 2016 Sep;116(3):38996.

[6] Spitznagel FA, Horvath SD, Guess PC, Blatz MB. Resin Bond to indirect composite and new ceramic/polymer materials: A review of the literature.J Esthet Restor Dent 2014;26(6):38293.

[7] Kawaguchi A, Matsumoto M, Hugashi $M$, Muira J, Minamino $T$, et al. "Bonding effectiveness of selfadhesive and conventional-type adhesive resin cements to CAD/CAM resin blocks. Part 2: Effect of ultrasonic and acid cleaning" Dental Materials Journal 2016; 35(1): 29-36.

[8] Furuse AY, Pirolo R, Rodrigues LK, Pizzatto E, Losso EM, et al. The efficacy of acid etching for removing contamination in layered dental restorations. Gen Dent 2012; 60: e312-e4.

[9] Sattabanasuk V, Shimada Y, Tagami $\mathrm{J}$. Effects of saliva contamination on dentin bond strength using all-in-one adhesives. Journal of adhesive dentistry, 2006, 8(5), 311-8

[10] Yoo HM, Oh TS, Pereira PN. Effect of saliva contamination on the microshear bond strength of one-step self-etching adhesive systems to dentin. Oper Dent. 2006;31:127-34.

[11] Chung CW, Yiu CK, King NM, Hiraishi $\mathrm{N}$, Tay FR. Effect of saliva contamination on bond strength of resin luting cements to dentin. J Dent. 2009 Dec;37(12):923-31.

[12] Poskus LT, Meirelles RS, Schuina VB, Ferreira LM, et al. Effects of different surface treatments on bond strength of an indirect composite to bovine dentin. Indian J Dent Res. 2015 May-Jun;26(3):289-94.

[13] Kirmali O, Barutcugil C, Harorli O, Kapdan A, Er K. Resin cement to indirect composite resin bonding: effect of various surface treatments. Scanning. 2015 Mar-Apr;37(2):89-94.

[14] Muñoz M, Luque I, Cabezas $X$, Carrasco R, Jerez G, et al. (2017). Efecto de los protocolos de limpieza y tratamientos de superficie precementación sobre la resistencia de unión de diferentes resinas compuestas indirectas. (Tesis de Pregrado). Universidad de Valparaíso, Valparaíso.

[15] Angkasith P, Burgess JO, Bottino MC, Lawson NC. Cleaning Methods for Zirconia Following Salivary Contamination. J Prosthodont. $2016 \mathrm{Jul}$; 25 (5): 375-9.

[16] Belli R, Guimarães JC, Filho AM, Vieira LC. Post-etching cleaning and resin/ceramic bonding: microtensile bond strength and EDX analysis. J Adhes Dent. 2010 Aug;12(4):295-303.

[17] Ishii R, Tsujimoto A, Takamizawa T, et al: Influence of surface treatment of contaminated zirconia on surface free energy and resin cement bonding. J Adv Prosthodont 2015;34:91-7

[18] Pitta J, Branco TC, Portugal J. Effect of saliva contamination and artificial aging on different primer/cement systems bonded to zirconia. J Prosthet Dent. 2018 May;119(5):833-9.

[19] Yang B, Wolfart S, Scharnberg $M$, Ludwig K, Adelung R, et al. Influence of Contamination on Zirconia Ceramic Bonding. J Dent Res. 2007 Aug;86(8):749-53.

[20] Sankar S, Kondas VV, Dhanasekaran SV, Elavarasu PK. Comparative evaluation of shear bond strength of zirconia restorations cleansed various cleansing protocols bonded with two different resin cements: An In vitro study. Indian J Dent Res. 2017;28(3):325-9.

[21] Ramezanian Nik I, Baradaran Naseri E, Majidinia S, Ramezanian Nik S, Jafari Giv M. Effect of Chlorhexidine and Ethanol on Microleakage of Composite Resin Restoration to Dentine. Chin J Dent Res. 2017;20(3):161-8. 
[22] Perdigao J, Sezinando A, Muñoz MA, Luque-Martínez IV, Loguercio AD. Prefabricated veneers-bond strengths and ultramorphological analyses. J Adhes Dent. 2014;16(2):137-46.

\section{ACKNOWLEDGEMENTS}

DDS. Mirko Riveros, DDS. Gabriela Jerez for contributing selflessly to the development of the project. In addition, Pablo Fuentes Díaz, Catalina Guerra Parker dental students who contributed to the writing of the manuscript.

\section{HOW TO CITE THIS ARTICLE}

Cañete C, Guerrero C, Martínez A, Gaete E. Effects of different pre-cementation cleaning protocols on adhesive bond strength in indirect composite resin restorations contaminated with saliva. Appli Sci Dent. 2021:1(1); 16-23

DOI: 10.22370/asd.2021.2.2.2878

ARTICULO IN PRESS

Applied Sciences in Dentistry, revista científica de la Facultad de Odontología de la Universidad de Valparaíso, de Acceso Abierto y de Publicación Continua.

Son aceptados trabajos originales e inéditos, abarcando cartas al editor, comunicaciones breves, artículos de investigación, casos clínicos y revisiones bibliográficas.

Correo electrónico de contacto:

contacto.asdj@uv.cl

editor.asdj@uv.cl

Página Web:

https://revistas.uv.cl/index.php/asid

Redes Sociales

Instagram@asd.journal

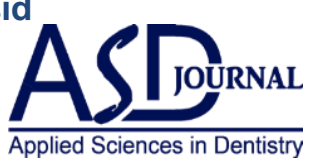

